\title{
Penerapan Harmony Search Algorithm untuk Menyelesaikan Economic Dispatch dengan Memperhitungkan Rugi-Rugi Transmisi
}

\author{
Purwoharjono ${ }^{\# 1}$

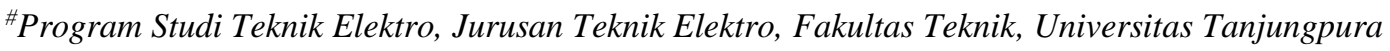 \\ Jalan Prof. Dr. H. Hadari Nawawi, Pontianak 78124 \\ ${ }^{1}$ purwo.harjonodee. untan.ac.id
}

\begin{abstract}
Abstrak- Penelitian ini bertujuan untuk menyelesaikan masalah Economic Dispatch (EC) menggunakan metode Artificial Intelligence (AI). Salah satu metode AI tersebut adalah Metode Harmony Search Algorithm (HSA). HSA ini merupakan suatu metode yang terinspirasi dari nada-nada musik yang di dengar. Simulasi HSA ini akan di implementasikan pada sistem 6 unit generator 425 MW yang ada di IEEE. Hasil simulasi menggunakan metode HSA dan metode Quadratic Programming (QP) dengan rugi-rugi transmisi adalah hasil metode HAS memperoleh biaya bahan bakar sebesar $24057,9070 \$ / \mathrm{h}$ dan rugi-rugi transmisi sebesar 7,1246 MW. Sedangkan menggunakan metode QP memperoleh biaya bahan bakar sebesar 24059,4257 \$/h dan rugi-rugi transmisi 7,1626 MW. Simulasi menggunakan metode HSA memperoleh biaya bahan bakar dan rugi rugi transmisi yang lebih kecil di bandingkan dengan menggunakan metode QP.
\end{abstract}

Kata kunci-Economic Dispatch, Artificial Intelligence, Harmony Search Algorithm, Quadratic Programming

\section{Pendahuluan}

\section{A. Latar Belakang}

Sejak lama pemakaian energi listrik ini mempunyai arti penting untuk industri. Sehingga pada dasawarsa terakhir, perhatian terhadap masalah energi menjadi sangat serius, di tengah kekhawatiran kemungkinan akan habisnya sumber energi ini di masa mendatang.

Di Indonesia, potensi minyak bumi yang kita miliki mempunyai peranan yang cukup penting, khususnya jika kita tinjau dari segi pemanfaatannya bagi pembangkit tenaga listrik. Pemakaian dan pengelolaan energi di negeri ini perlu dilaksanakan, dengan salah satu tujuan dapat memberikan arti dan manfaat bagi kesejahteraan manusia.

Seiring pertumbuhan energi listrik dari tahun ke tahun ini menuntut pihak PT. PLN (Persero) untuk terus menerus berupaya meningkatkan penyediaan daya listriknya. Upaya ini antara lain adalah dengan memperbesar daya pembangkit listrik atau menambah jumlah unit mesin pembangkit listrik pada suatu pusat pembangkit sehingga akan diperoleh daya listrik yang lebih besar agar dapat mengantisipasi perkembangan beban. Peningkatan daya listrik terpasang ini, didukung potensi sumber energi yang di miliki, baik sumber tenaga air, uap, gas, panas bumi maupun sumber energi yang lain [1].

Pengoperasian secara ekonomis pembangkitan tenaga listrik ini dimaksudkan dapat mengatur daya keluaran dari pada mesin pembangkit sedemikian rupa sehingga biaya operasi pembangkitan tersebut dapat ditekan seminimal mungkin yang dapat dilakukan dengan menggunakan analisis Economic Dispatch. Dengan menggunakan Economic Dispacth ini, pengoperasian secara ekonomis pembangitan tenaga listrik ini dapat memberikan keuntungan-keuntungan sebagai berikut: pengurangan biaya operasi yang pada gilirannya dapat mengurangi biaya produksi energi listrik; penghematan konsumsi bahan bakar sehingga dapat membantu mensukseskan program pemerintah dalam kampanye hemat energi dan konservasi energinya; Pengurangan rugi-rugi energi listrik total sehingga dapat meningkatkan kualitas pelayanan tenaga listrik; dan memperpanjang umur (masa pakai) dari mesinmesin pembangkit [2].

Metode konvensional yang biasa digunakan untuk penyelesaian hal ini adalah metode Lagrange, metode Gradien, Quadratic Programing dan metode Newton Rapshon [1-3].

Beberapa penelitian yang menggunakan metode AI, seperti: Equilibrium Optimizer [4], Particle Swarm Optimization [5-6], bat algorithm [7], Neurocomputing [8], ACO-ABC-HS optimization algorithm [9].

Salah satu dari AI ini adalah metode HSA. Metode HSA ini ditemukan oleh Zong Woo Geem pada tahun 2001. Metode HSA ini merupakan metode yang terinspirasi dari nada-nada musik yang di dengar [10-15].

Hasil simulasi dari metode HSA ini diharapkan nilai rugi-rugi daya listriknya lebih kecil di bandingkan dengan menggunakan metode QP. 


\section{B. Urgensi Penelitian}

Pengoperasian yang didasarkan pada operasi ekonomis menjadi semakin penting dan populer akibat meningkatnya biaya operasi secara signifikan. Peningkatan biaya operasi ini adalah naiknya harga bahan bakar yang dipicu oleh adanya krisis energi dan moneter. Biaya bahan bakar merupakan komponen utama dari biaya operasi pembangkitan tenaga listrik. Biaya bahan bakar ini dapat mencapai $75 \%$ s/d $85 \%$ dari total biaya operasi.

Metode konvensional yang biasa digunakan untuk penyelesaian masalah ini adalah metode Lagrange, metode Gradien, dan metode Newton Raphson.

Pada penelitian ini akan melakukan inovasi baru dalam penyelesaian masalah tersebut menggunakan AI. Salah satu dari AI ini adalah metode HSA.

\section{Metode}

Langkah penyelesaian masalah Economic Dispatch menggunakan HSA adalah sebagai berikut :

1. Data Masukkan yang dimaksud adalah data yang berupa dari data HSA yaitu berdasarkan dari HMS, Bandwith, HMCR, dan PAR. Sedangkan untuk data sistem berupa dari koefesien generator, $\mathrm{P}_{\min }$ dan $\mathrm{P}_{\max }$ generator, dan rugi-rugi transmisi;

2. Membentuk Inisialisasi Parameter awal berfungsi untuk mengatur nilai awal dari data HSA;

3. Decode HSA adalah menjalankan program yang sudah diatur saat setelah mensetting data HSA;

4. Dalam Tahap ini telah menghitung biaya pembangkit dan kesetimbangan daya untuk dianalisa agar tidak melewati batas batas daya pembangkit yang telah ditentukan;

5. Untuk tahap ini setelah didapatkan nilai yang diinginkan akan dievaluasi nilai Harmony untuk dimasukkan kedalam Harmony Memory;

6. Operator algoritma akan melakukan improvisasi, pergantian, dan pemberhentian kriteria guna mendapatkan hasil yang terbaik dari Harmony Memory;

7. Pada tahap ini akan dievaluasi lagi mana yang akan diambil untuk dijadikan nilai yang optimal dari baik menjadi yang lebih baik, jika nilai masih belum terkonvergensi maka akan dilakukan inisialisasi awal sehingga mendapatkan hasil yang terbaik;

8. Hasil dari nilai HSA terbaik dengan keluaran harga yang beragam selama 15 kali diuji untuk dipilih yang mana lebih ekonomis;

9. Setelah didapatkan hasil biaya bahan bakar yang optimal untuk metode HSA, maka langkah selanjutnya mencari biaya bahan bakar dengan menggunakan metode Quadratic Programming;

10. Langkah pertama untuk mengimplementasikan QP kedalam Economic Dispatch dengan membuat inisialisasi awal yaitu membuat prosedur dan batasan terendah dari setiap unit pembangkit;

11. Menentukan alokasi daya dari masing-masing pembangkit dengan melakukan subtitusi;
12. Hitung rugi-rugi daya dan bila tanpa menggunakan rugi rugi matrik rugi-rugi diberi nilai 0 ;

13. Periksa konvergensi sehingga mencapai nilai yang optimal;

Hasil dari HSA dan QP selanjutnya akan dianalisa untuk mendapatkan biaya bahan bakar yamg optimal, maka akan dibandingkan untuk setiap selisih harga dalam setiap pengujian yang dilakukan;

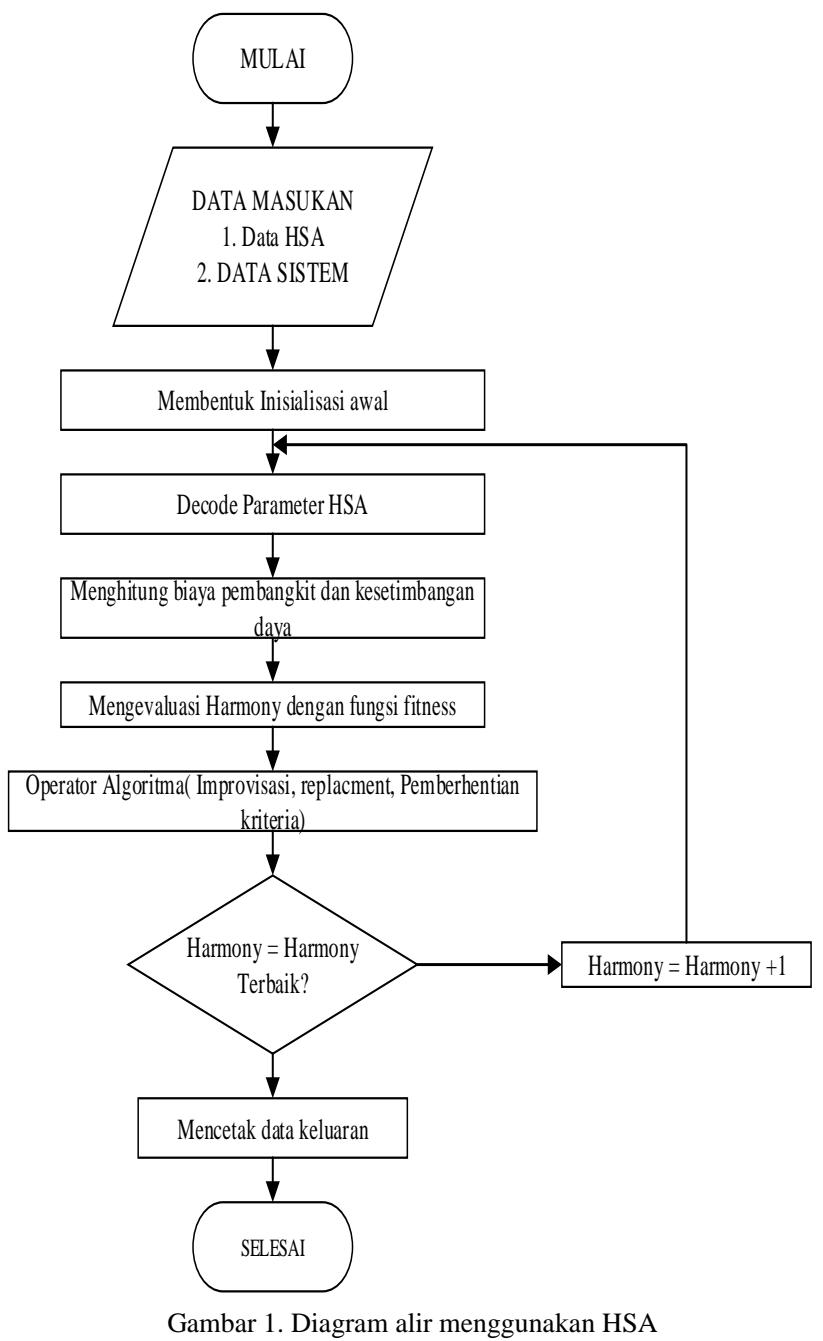

\section{HASIL DAN PEMBAHASAN}

\section{A. Data Sistem 6 Unit Generator}

Karakteristik unit pembangkit ditunjukan oleh suatu fungsi yang menjelaskan akan kebutuhan bahan bakar dari suatu unit pembangkit dalam menghasilkan daya. Data yang digunakan dalam penelitian ini adalah data pada sistem 6 unit generator dengan standar IEEE (Institue of Electrical and Electronics Engineers). Data tersebut terdiri dari data jumlah unit Generator, batasan unit generator dan koefesien biaya bahan bakar pada tiap unit generator.

Adapun untuk parameter kontrol HSA adalah sebagai berikut : 
TABEL I

PARAMETER HSA

\begin{tabular}{|l|l|l|}
\hline \multicolumn{1}{|c|}{ PARAMETER } & Simbol & Nilai( HSA) \\
\hline Harmony Memory Size & HMS & 100 \\
\hline Bandwith & Bw & 0,1 \\
\hline $\begin{array}{l}\text { Harmony Memory Consindering } \\
\text { rate }\end{array}$ & HMCR & 0.95 \\
\hline Pitch Adjusment Rate & PAR & 0.3 \\
\hline Jumlah maksimal iterasi & Maxitr & 10000 \\
\hline
\end{tabular}

TABEL II

DATA SISTEM 6 UNIT GENERATOR

\begin{tabular}{|c|c|c|c|c|c|}
\hline $\begin{array}{c}\text { Uni } \\
\mathrm{t}\end{array}$ & $\begin{array}{c}\mathrm{Pi}^{\mathrm{Min}} \\
(\mathrm{MW})\end{array}$ & $\begin{array}{c}\mathrm{Pi}^{\mathrm{Max}} \\
(\mathrm{MW})\end{array}$ & $\begin{array}{c}\mathrm{a}_{\mathrm{i}} \\
(\$ / \mathrm{MW})\end{array}$ & $\begin{array}{c}\mathrm{b}_{\mathrm{i}} \\
(\$ / \mathrm{MW})\end{array}$ & $\begin{array}{c}\mathrm{c}_{\mathrm{i}} \\
(\$ / \mathrm{MW})\end{array}$ \\
\hline 1 & 10 & 125 & 0,15247 & 38,53973 & 756,79886 \\
\hline 2 & 10 & 150 & 0,10587 & 46,15616 & 451,32513 \\
\hline 3 & 35 & 225 & 0,02803 & 40,39655 & 1049,9977 \\
\hline 4 & 35 & 210 & 0,03546 & 38.30553 & 1243,5311 \\
\hline 5 & 130 & 325 & 0,02111 & 36.32782 & 1658,5696 \\
\hline 6 & 125 & 315 & 0,01799 & 38.27041 & 1356,6592 \\
\hline
\end{tabular}

Dimana :

$\mathrm{Pi}^{\mathrm{Min}}$ : batas daya generator yang paling rendah

$\mathrm{Pi}^{\mathrm{Max}}$ : batas daya generator yang paling tinggi

Adapun koefisien matriks rugi-rugi transmisi dikali $10^{-3}$ adalah :

$=\left[\begin{array}{llllll}0,140 & 0,017 & 0,015 & 0,019 & 0,026 & 0,022 \\ 0,017 & 0,060 & 0,013 & 0,016 & 0,015 & 0,020 \\ 0,015 & 0,013 & 0,065 & 0,017 & 0,024 & 0,019 \\ 0,019 & 0,016 & 0,017 & 0,071 & 0,030 & 0,025 \\ 0,026 & 0,015 & 0,024 & 0,030 & 0,069 & 0,032 \\ 0,022 & 0,020 & 0,019 & 0,025 & 0,032 & 0,085\end{array}\right]$

\section{B. Karakteristik Konvergensi Menggunakan Metode HSA}

Hasil simulasi sistem 6 unit generator menggunakan Metode Harmony Search Algorithm ini dikatakan berhasil jika karakterisiknya konvergen, seperti dapat dilihat pada gambar 2.

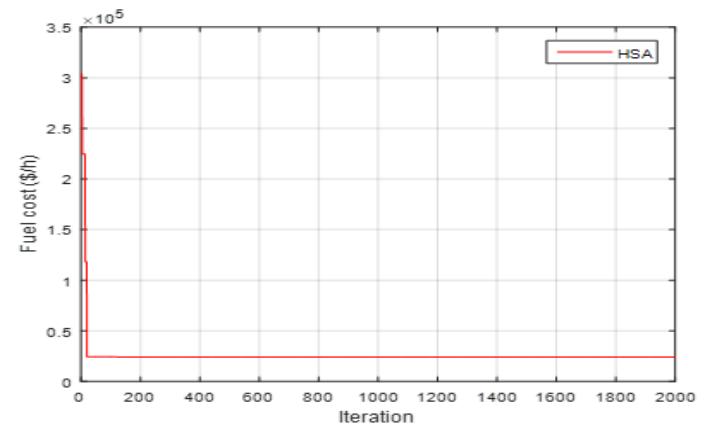

Gambar 2. Karakteristik konvergensi menggunakan metode harmony search algorithm

Pada Gambar 2. terlihat bahwa simulasi sistem 6 unit generator menggunakan Metode HSA ini dapat digunakan untuk melakukan simulasi pembangkitan ekonomis pada system 6 unit generator.
C. Hasil Simulasi Menggunakan Metode HSA dengan Rugi-Rugi Transmisi

Hasil simulasi sistem 6 Unit Generator menggunakan metode HSA dengan rugi-rugi transmisi ini dilakukan sebanyak 15 kali tes uji. Dari hasil simulasi ini diambil nilai biaya bahan bakar pembangkitan terendah, seperti pada Tabel 3.

TABEL III

HASIL SimUlasi MENGGUNAKAN METODE HSA DENGAN RUGI-RUGI TRANSMISI

\begin{tabular}{|c|c|r|}
\hline No & Unit Generator & Daya Beban (MW) \\
\hline 1 & P1 & 16,9611 \\
\hline 2 & P2 & 10,0001 \\
\hline 3 & P3 & 54,8451 \\
\hline 4 & P4 & 69,6748 \\
\hline 5 & P5 & 154,1144 \\
\hline 6 & P6 & 126,5291 \\
\hline 7 & Biaya Bahan Bakar (\$/h) & 24057,9070 \\
\hline 8 & Rugi-Rugi Transmisi (MW) & 0,790512 \\
\hline 9 & Komputasi (detik) & \\
\hline
\end{tabular}

Pada Tabel 3 terlihat bahwa hasil simulasi 6 Unit Generator menggunakan Metode HSA dengan Rugi-Rugi Transmisi pada Daya Beban $425 \mathrm{MW}$ ini, diambil dari hasil simulasi dengan nilai biaya bahan bakar pembangkitan nya paling rendah, yaitu sebesar 24057.9070 \$/h dan rugi-rugi transmisi sebesar 7.1246 MW.

\section{Hasil Simulasi menggunakan Metode HSA Tanpa Rugi-Rugi Transmisi}

Hasil simulasi system 6 Unit Generator menggunakan metode HSA tanpa rugi-rugi transmisi ini dilakukan sebanyak 15 kali tes uji. Dari hasil simulasi ini diambil nilai biaya bahan bakar pembangkitan terendah, seperti pada Tabel 4.

TABEL IV

HASIL Simulasi MENGGUNAKAN METODE HSA TANPA RUGI-RUGI TRANSMISI

\begin{tabular}{|c|c|r|}
\hline No & Unit Generator & Daya Beban (MW) \\
\hline 1 & $\mathrm{P} 1$ & 14,5607 \\
\hline 2 & $\mathrm{P} 2$ & 10,0000 \\
\hline 3 & 3 & 46,0813 \\
\hline 4 & $\mathrm{P} 4$ & 65,9100 \\
\hline 5 & $\mathrm{P} 5$ & 157,5569 \\
\hline 6 & $\mathrm{P} 6$ & 130,8911 \\
\hline 7 & Biaya Bahan Bakar (\$/h) & 23747,5650 \\
\hline 8 & Rugi-Rugi Transmisi (MW) & 0,0000 \\
\hline 9 & Komputasi (detik) & 0,247017 \\
\hline
\end{tabular}

Pada Tabel 4 terlihat bahwa hasil simulasi 6 Unit Generator menggunakan Metode HSA dengan Rugi-Rugi Transmisi pada Daya Beban 425 MW ini, diambil dari hasil simulasi dengan nilai biaya bahan bakar pembang kitan nya paling rendah, yaitu sebesar 23747,5650 \$/h dan rugi-rugi transmisi sebesar $0 \mathrm{MW}$.

\section{E. Hasil Simulasi Menggunakan Metode QP dengan Rugi- Rugi Transmisi}

Hasil simulasi system 6 Unit Generator menggunakan metode QP dengan rugi-rugi transmisi ini dilakukan sebanyak 15 kali tes uji. Dari hasil simulasi ini diambil nilai 
biaya bahan bakar pembangkitan terendah, seperti pada Tabel 5.

TABEL V

HASIL SimULASI MENGGUNAKAN METODE QP DENGAN RUGI-RUGI TRANSMISI

\begin{tabular}{|c|c|r|}
\hline No & Unit Generator & \multicolumn{1}{|c|}{ Daya Beban (MW) } \\
\hline 1 & P1 & 16,2516 \\
\hline 2 & P2 & 10,0000 \\
\hline 3 & P3 & 55,4772 \\
\hline 4 & P4 & 69,7205 \\
\hline 5 & P5 & 154,3874 \\
\hline 6 & P6 & 126,3259 \\
\hline 7 & Biaya Bahan Bakar (\$/h) & 24059,4257 \\
\hline 8 & Rugi-Rugi Transmisi (MW) & 7,1626 \\
\hline 9 & Komputasi (detik) & 0,030999 \\
\hline
\end{tabular}

Pada Tabel 5 terlihat bahwa hasil simulasi 6 Unit Generator menggunakan metode QP dengan Rugi-Rugi Transmisi pada Daya Beban 425 MW ini, diambil dari hasil simulasi dengan nilai biaya ahan bakar pembangkitan nya paling rendah, yaitu sebesar 24059,4257 \$ $/$ h dan rugirugi transmisi sebesar 7,1626 MW.

\section{F. Hasil Simulasi menggunakan Metode QP Tanpa Rugi- Rugi Transmisi}

TABEL VI

Hasil Simulasi MENGgunaKan Metode QP TANPA RUgI-RUgi TRANSMISI

\begin{tabular}{|c|c|r|}
\hline No & Unit Generator & Daya Beban (MW) \\
\hline 1 & P1 & 14,5607 \\
\hline 2 & P & 10,0000 \\
\hline 3 & P3 & 46,0813 \\
\hline 4 & P4 & 65,9100 \\
\hline 5 & P & 157,5569 \\
\hline 6 & P6 & 130,8911 \\
\hline 7 & Biaya Bahan Bakar (\$/h) & 23747,5650 \\
\hline 8 & Rugi-Rugi Transmisi (MW) & 0,0000 \\
\hline 9 & Komputasi (detik) & 0,060730 \\
\hline
\end{tabular}

Hasil simulasi system 6 Unit Generator menggunakan metode QP tanpa rugi-rugi transmisi ini dilakukan sebanyak 15 kali tes uji. Dari hasil simulasi ini diambil nilai biaya bahan bakar pembangkitan terendah, seperti pada Tabel 6.

Pada Tabel 6 terlihat bahwa hasil simulasi 6 Unit Generator menggunakan metode QP Tanpa Rugi-Rugi Transmisi pada Daya Beban $425 \mathrm{MW}$ ini, diambil dari hasil simulasi dengan nilai biaya bahan bakar pembangkitan nya paling rendah, yaitu sebesar 23747,5650 \$/h dan rugi-rugi transmisi sebesar 7,1626 MW.

\section{G. Perbandingan Hasil Simulasi sistem 6 unit Generator menggunakan Metode HSA dan Metode QP Dengan Rugi-Rugi Transmisi}

Hasil simulasi system 6 Unit Generator menggunakan Perbandingan Metode HSA dan metode QP dengan rugirugi transmisi, seperti pada Tabel 7 .
TABEL VII

PERBANDINGAN HASIL SimUlasi 6 Unit GeNERATOR METODE HSA DAN QP PADA DAYA BEBAN 425 MW DENGAN RUGI-RUGI TRANSMIS

\begin{tabular}{|c|l|r|r|}
\hline No & \multicolumn{1}{|c|}{ Uraian } & \multicolumn{1}{c|}{$\boldsymbol{H S A}$} & \multicolumn{1}{c|}{$\boldsymbol{Q P}$} \\
\hline 1 & Biaya bahan bakar(\$/h) & 24057,9070 & 24059,4257 \\
\hline 2 & $\begin{array}{l}\text { Dengan Rugi-Rugi } \\
\text { Transmisi (MW) }\end{array}$ & 7,1246 & 7,1626 \\
\hline 4 & Komputasi (Detik) & 0,790512 & 0,030999 \\
\hline
\end{tabular}

Pada Tabel 7 ini, hasil simulasi untuk beban 425 MW dengan memperhitungkan rugi-rugi transmisi metode HSA memiliki harga biaya bahan bakar yang ekonomis dibandingkan dengan metode QP dengan selisih nilainya sebesar 1,5187 \$/h dan memiliki selisih harga ekonomis yang sedikit kecil dari metode QP yang dibandingkan.

\section{H. Perbandingan Hasil Simulasi sistem 6 unit Generator} menggunakan Metode HSA dan Metode QP Tanpa Rugi-Rugi Transmisi

Hasil simulasi system 6 Unit Generator menggunakan Perbandingan Metode HAS dan metode QP dengan rugirugi transmisi, seperti pada Tabel 8 .

TABEL VIII

PERBANDingan Hasil SimUlasi MENGGUNAKAN METODE HSA DAN QP TANPA RUGI-RUGI TRANSMISI

\begin{tabular}{|c|l|r|r|}
\hline No & \multicolumn{1}{|c|}{ Uraian } & \multicolumn{1}{c|}{$\boldsymbol{H S A}$} & \multicolumn{1}{c|}{$\boldsymbol{Q P}$} \\
\hline 1 & Biaya bahan bakar $(\$ / \mathrm{h})$ & 23747,5650 & 23747,5650 \\
\hline 2 & $\begin{array}{l}\text { Tanpa Rugi-Rugi } \\
\text { Transmisi (MW) }\end{array}$ & 0 & 0 \\
\hline 4 & Komputasi (Detik) & 0,247017 & 0,060730 \\
\hline
\end{tabular}

Pada Tabel 8 ini, hasil simulasi untuk beban 425 MW tanpa memperhitungkan rugi-rugi transmisi metode HSA memiliki harga biaya bahan bakar yang sama ekonomis dengan metode QP.

\section{KESIMPULAN}

Dari hasil simulasi penelitian ini menggunakan metode HAS dan metode QA dengan rugi-rugi transmisi adalah metode HAS memperoleh biaya bahan bakar sebesar 24057,9070 \$/h dan rugi-rugi transmisi sebesar $\quad 7,1246$ MW. Sedangkan menggunakan metode QP memperoleh biaya bahan bakar sebesar 24059,4257 \$/h dan rugi rugi transmisi 7,1626 MW.

\section{UCAPAN TERIMA KASIH}

Kami sangat berterima kasih kepada Kementrian Riset, Teknologi dan Pendidikan Indonesia dan Fakultas Teknik Universitas Tanjungpura dan Laboratorium Distribusi dan Sistem Transmisi Fakultas Teknik Untan untuk semua fasilitas dan dana DIPA yang disediakan selama periode penelitian ini.

\section{REFERENSI}

[1] Arnawan Hasibuan, Robi Kurniawan, Muzamir Isa, Mursalin, "Economic Dispatch Analysis Using Equal Incremental Cost Method with Linear Regression Approach," Journal of Renewable Energy, Electrical, and Computer Engineering, Vol.1, No.1, March 2021

[2] M. S. P. Subathra, S. E. Selvan, T. A. A. Victoire, A. H. Christinal, and U. Amato, "A hybrid with cross-entropy method and sequential 
quadratic programming to solve economic load dispatch problem," IEEE Systems Journal, vol. 9, no. 3, pp. 1031-1044, 2015.

[3] R. P. Parouha and K. N. Das, "A novel hybrid optimizer for solving Economic Load Dispatch problem," International Journal of Electrical Power \& Energy Systems, vol. 78, pp. 108-126, 2016.

[4] Osea Zebua, I Made Ginarsa, I Made Ari Nrartha, "Penyelesaian Masalah Economic Dispatch Menggunakan Equilibrium Optimizer,” Jurnal Teknik Elektro, vol.13, no.1, Januari-Juni 2021

[5] Jianxia Zhang, Jianxin Zhang, Feng Zhang, Minglu Chi, and Linbin Wan, "An Improved Symbiosis Particle Swarm Optimization for Solving Economic Load Dispatch Problem," Journal of Electrical and Computer Emgimeering, 05 Januari 2021.

[6] J. B. Park, Y. W. Jeong, and J. R. Shin, "An improved particle swarm optimization for nonconvex economic dispatch problems," IEEE Transactions on Power Systems, vol. 25, no. 1, pp. 156-166, 2020.

[7] B. R. Adarsh, T. Raghunathan, T. Jayabarathi, and X.-S. Yang, "Economic dispatch using chaotic bat algorithm," Energy, vol. 96, pp. 666-675, 2016

[8] X. He, Y. Rao, and J. Huang, "A novel algorithm for economic load dispatch of power systems," Neurocomputing, vol. 171, pp. 14541461, 2016.
[9] T. Sen and H. D. Mathur, "A new approach to solve Economic Dispatch problem using a Hybrid ACO-ABC-HS optimization algorithm," International Journal of Electrical Power \& Energy Systems, vol. 78, no. 78, pp. 735-744, 2016

[10] Mahima Dubey, Vijay Kumar, Manjit Kaur, Thanh-Phong Dao, “A Systematic Review on Harmony Search Algorithm: Theory, Literature, and Applications," Mathematical Problems in Engineering, 16 April 2021.

[11] J. Yi, C. Lu, and G. Li, "A literature review on latest developments of Harmony Search and its applications to intelligen manufacturing," Mathematical Biosciences and Engineering, vol. 16, no. 4, pp. 2086-2117, 2019.

[12] Y.-W. Jeong, S.-M. Park, Z. W. Geem, K.-B. Sim, and ", "Advanced parameter-setting-free harmony search algorithm," Applied Sciences, vol. 10, no. 7, 2020.

[13] G. Li and H. Wang, "Improved harmony search algorithm for global optimization," Chinese Control and Decision, vol. 21, 2018.

[14] H.-B. Ouyang, L.-Q. Gao, S. Li, X.-Y. Kong, Q. Wang, and D.-X. Zou, "Improved harmony search algorithm: LHS," Applied Mathematics and Computation, vol. 53, pp. 133-167, 2017.

[15] M. Shafaati and H. Mojallali, "IIR filter optimization using improved chaotic harmony search algorithm," Automatika, vol. 59, no. 3-4, pp. 331-339, 2018. 